Edita Bartnikaitè

Vytautas Magnus University

Lithuania

Vilma Bijeikienè

Vytautas Magnus University

Lithuania

\title{
PERSPECTIVES IN LEGAL ENGLISH IN-SERVICE EDUCATION: NEEDS ANALYSIS IN LITHUANIAN CONTEXT
}

\begin{abstract}
Legal English, being among the most complex and multifaceted areas of English for Specific Purposes (ESP), has duly received considerable attention on the part of linguists, discourse and learner needs' analysts, sociolinguists and ESP researchers (Cheng and Cheng, 2014; Hafner, 2013; Hartig and Lu, 2014; Huhta et al, 2013; Shuy 2001). Most research has been carried out to investigate lexical, syntactic, grammatical and other communicative competences of law students in various cycles of higher education. An area that is still highly in need of examination is the development of communicative competences of Legal English among law practitioners who might have had a course of Legal English in their law studies and face with an urge of revision or might have not been introduced to Legal English whatsoever. In light of these observations, the present study examines the needs and problems regarding the use of general and legal English faced by 34 law practitioners, namely lawyers and judges working at two law companies and a district court in Kaunas, Lithuania. The study assumes qualitative methodology including a semi-structured interview and a questionnaire. The results have revealed that communicative competence of legal practitioners gained during their formal education does not meet the demands of their legal practice. While skills of general English appear not to cause many problems, skills of legal English are not developed to an adequate level. Therefore, as the study shows, it is absolutely inevitable to develop and offer in-service education of Legal English carefully attuned to the diverse levels of competences and needs of legal practitioners.

Keywords: Legal English, English for Specific Purposes (ESP), General English, communicative competence, in-service education.
\end{abstract}

\section{Introduction}

The era of dramatically increasing globalisation has witnessed the development of inextricable commercial, cultural and academic links which 
have consequently determined that English has been increasingly enjoying the status of academic and professional lingua franca. Multinational and transnational business companies and corporations, international projects of science, culture and art have turned to rely on English as a vital vein of their correspondence and communication. English seems not to dispense with even in situations when it is not the first language of any of the interlocutors. As a result, the development of adequate communicative skills and competencies of English not only in the contexts of daily routines but also in particular fields of professional practice has become a pivotal objective that could enable a specialist to strive for academic and professional success. In contrast, the lack of fluency in general and professional use of English, or in other words, the lack of feeling comfortable with English in one's professional practice, can and does become a fatal impediment to successful career.

In light of the observations above, Lithuania stands out as a country where the need of English as an academic and professional lingua franca and concomitantly the need for the well-developed competences of English among its human resources are more acute than in other countries. Such conclusion could be drawn on geographic, demographic and socio-political characteristics of Lithuania. With the Independence re-established in 1990, Lithuania opened boarders not only for the physical movement of its people all over the world but also for the incorporation into and development of international projects and companies. Moreover, being a small country whatsoever, Lithuania has been still losing population due to the rather intensive emigration ${ }^{1}$, which at the same time, however, has given an extra push towards intensification of international cooperation. In regard to legal contexts, English medium activities have been on increase as well. Joint law companies, transnational cases, or legal services to foreign nationals and immigrant could be named as examples of legal practices sensitive and bound to good competences of English.

At the Institute of Foreign Languages at Vytautas Magnus University (VMU hereinafter), Kaunas, Lithuania, the situation described above is mirrored by the increase in the interest of legal practitioners in in-service courses of legal English. The Institute provides a broad spectrum of language teaching, assessment, translation and interpretation services to university students, academic and non-academic staff as well as people outside the university community. The experience in delivering Legal English as a compulsory course to university students and the insights gained from giving in-service courses to legal practitioners have raised questions regarding the communicative needs of those working in legal contexts. This experience has also proposed research opportunities directed toward better quality of 
language teaching services and has helped to shape out the research aims for the present study. The overarching aim of the present study is to analyse the needs for in-service development of English communicative competences for legal practitioners (cf. Chovancova, 2014). This aim embraces three main objectives, namely (1) to analyse the participants' experience in learning English; (2) to examine their needs, expectations and demands relevant to the use of English in professional legal contexts; and (3) to offer improvements for in-service Legal English programmes.

\section{Theoretical background}

At the Lisbon meeting of the European Council in March 2000, the mission set for the EU was to become the most competitive and dynamic knowledge-based economy in the world, which should be capable of sustainable economic growth offering more and better jobs and enhanced social cohesion. Lifelong learning, including in-service education, is a fundamental aspect of this strategy, essential not only to better competitiveness and employability in the EU but also to the increased social inclusion and personal development. As stated in the joint European Commission and Council communication on new priorities for European cooperation in education and training (2015), numerous requests by stakeholders, including learners, providers and employers, for a simpler, more user-friendly and more flexible approach to implementing the lifelong learning paradigm guide to an intensified coordination between various education and training sectors and a strongly integrated overall policy framework.

In this context, adult learning remains a specific challenge. The urge for adults to learn throughout life needs to be reconsidered and given special attention and has to be acknowledged as an integral part of a continuum, delivering skills from early childhood to later life. The well-known expert in the fields of adult and continuous education as well as in lifelong learning Jarvis (2012) points out that the term adult refers to a social status more than to a biological age since there are differences throughout the world in connection to the stage of life when adulthood is achieved. Therefore, it would be significant to recognise that the learning process does not occur in social isolation and that manifestation of different forms of learning may be the aftermath of social and cultural circumstances the learner was born into or got in later in his or her life. Thus, it is beyond doubt that psychological, social and cultural aspects affecting the lifelong learning process in adult education need to be taken into consideration. 
Despite extensive criticism for the lack of empirical data, most theories on adult education still invoke the andragogical learner-centred model, proposed by Knowles et al (2015), with the teacher acting as a facilitator. This model is comprised of several dimensions different from those of the traditional teacher-centred pedagogical model, namely (1) the need to know (i.e. it is highly important for adult learners to clearly perceive why they have to learn something before committing themselves to learning it), (2) the learners' self-concept (i.e. adults assume responsibility for their own decisions and for their own lives) and (3) the role of the learners' experience. In other words, adults undertake their educational activities with both a more significant amount and a different quality of experience in comparison to that of young learners. This difference determines that in a group of adults there will be a wider range of individual variation than in a group of the young. Adults make more heterogeneous groups due to the variety in their background, learning style, motivation, needs, interests, and goals. Therefore, in adult education more emphasis is placed on individualisation of teaching and learning strategies.

To continue with the andragogical model of Knowles et al (2015), the other significant dimensions of this model include (4) readiness to learn, (5) orientation to learning and (6) motivation. Adults are readily willing to develop those skills which they need to have and be able to employ effectively in their particular real-life situations. Moreover, in comparison to young learners, whose learning patterns are more subject-oriented, adult learners are more task-centred or problem-oriented in their attitude to learning. Thus, they are more motivated to learn to the extent that they appreciate that learning will help them to perform their tasks easier and to solve their daily routine problems. They gain new knowledge, skills, values, and attitudes most efficiently when their competences are developed in the context of application to real-life situations. Adults are rather sensitive to external motivators like better job opportunities, promotion chances, higher salaries, etc., but the most powerful motivators are internal pressures, namely the aspirations for improved job satisfaction, self-esteem, quality of life and other motives.

Tough (1979) states that most adults are motivated to continue growing and advancing, but this motivation is frequently hampered by such factors as negative self-esteem, often limited access to opportunities or resources, time restrictions, and programs that violate the principles of adult education. Smith (2002) maintains that in focusing on the concept of informal learning, Knowles et al (2015) was making references to the 'friendly and informal climate' in many adult learning situations, the flexibility of the 
process, the use of experience and commitment of participants. The idea of the demand for specific learning environment for adult learners is reiterated in Galbraith's (2004) research in a form of principles to be employed by teachers of adults. It entails an appropriate philosophy to guide the educational encounter through understanding the variability and diversity of adult learners, creating conducive psychosocial climate, presenting challenging teaching and learning interactions, giving learners the opportunities to scrutinise, question and develop alternative ways of thinking, authenticity and credibility of the educational encounter.

\section{Data and methodology}

As already mentioned before, the participants of the study are legal practitioners who applied to take or took a course of English offered by VMU Institute of Foreign Languages in the years 2014 and 2015. It is a small-scale qualitative study based on informal interviews with the participants and a questionnaire composed of closed and open questions (cf. Litosseliti, 2010). Closed questions were aimed at eliciting participants' experience in learning English including different cycles of formal education and means of nonformal learning such as courses for the public, in-service courses or private lessons. Closed questions were also used to request participants to assess their communicative skills and competences regarding general English and legal English and to indicate what types of informal practices of English they follow in their professional and daily life. Open questions were employed to extract information about the functions of English that participants need in their work routines, the skills of English that they would like to improve most and the obstacles they might have faced with while aiming to improve their English.

Participants of the study represent three legal institutions including two law companies and Kaunas district court. In total there were 34 legal practitioners whose age distribution is presented in Figure 1 (one participant did not indicate his/her age).

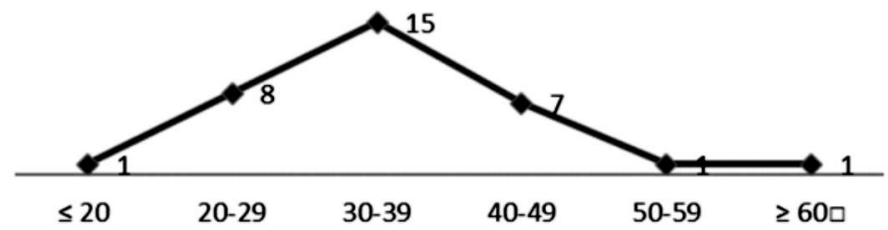

Figure 1. Age distribution of participants 
The majority of participants ranged from of 20 to 49 years of age with the most numerous group of 30-39 years. This distribution has important implications for the study, namely the majority of the participants are either at the beginning or at the peak of their career and must be keenly interested in advancing their skills and competences for professional progress and success.

\section{Results and discussion}

\section{Experience in learning and using English}

Communicative skills strongly pertain to the principles of life-long learning and can be seen as a continuous endeavour of a person over different stages of his/her education and later in his/ her work context (see Figure 2).

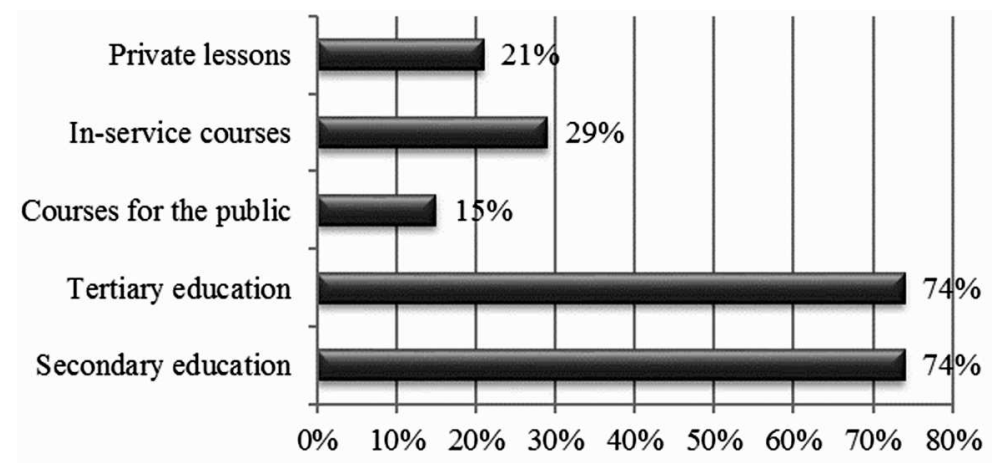

Figure 2. Experience in learning English

As could have been predicted from the professionally active age of the participants (see section on Data and methodology), they demonstrate their rich involvement in the development of their communicative skills of English. The majority of participants $(74 \%)$ studied English at secondary school as well as at the tertiary level of education. Moreover, quite a substantial number, amounting to $29 \%$, have taken in-service education courses of English which can be expected to be more closely pertaining to the specific work functions that participants undertake in their work context. Finally, slightly smaller but still considerable numbers of participants, $21 \%$ and $15 \%$ respectively, have assumed private lessons or courses for the public. Importantly, there were no questionnaires where at least a single option of the given alternatives would not have been indicated, showing us that all of the participants have been exposed to the development of the communicative competence of English to a certain extent. 
Such results, firstly, demonstrate that formal education does not satisfy communicative needs of English of legal practitioners and some of them look for more forms of competence development. The results also show that legal practitioners, more specifically participants of this study, have high motivation in perfecting their communicative skills of English. The latter assumption is strengthened by the facts that some of the participants marked all of the options of learning English given in Figure 2 and that some of them gave remarks in the informal interviews about their dissatisfaction with their current competences. Even those of the participant who had scored high on the placement test of English (provided by VMU Institute of Foreign Languages) complained about the inadequacies of their communicative competences expressing their eagerness for perfection such as to make their pronunciation closer to the standard accent or to be able to write contract texts as their counterparts from English speaking countries. Comments in the open questions of the questionnaire reveal that participants who had not studied English in institutions of formal education and gained their current skills only through the forms of non-formal competence development are not only unsatisfied with their skills but also strongly demotivated and sceptical about their capacity to ever learn English to the level they would feel comfortable with. This situation poses a strong challenge to teachers to, first of all, make adult learners believe in their future progress and, secondly, adapt the methods as to make their progress real.

Given that language learning can take place not only as part of formal and non-formal education, but can also be more or less subconsciously attained through the involvement in various work and leisure related routines, participants of the study were asked to indicate in what context they happen to use English (see Figure 3).

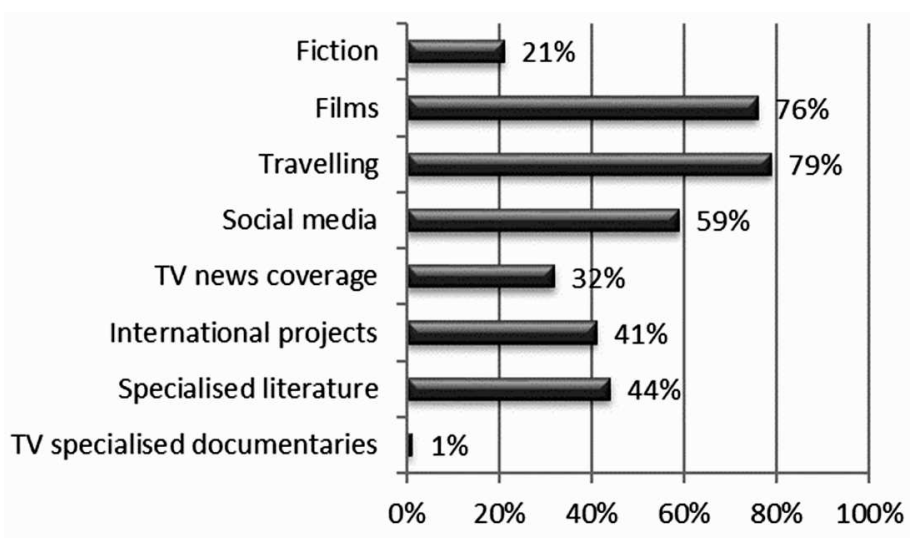

Figure 3. Informal practices of using English 
The overall view presented in Figure 3 reveals that participants are quite active in encountering and using English as productive and receptive skills in various informal contexts except for watching TV documentaries. Most of the participants come across English while travelling (79\%), watching films $(76 \%)$ and using social media (59\%). That could be beneficial in improving receptive skills, especially listening in the case of watching films, and to some extent productive skills in the form of oral communication while travelling and written communication in social media. Reading specialised literature $(44 \%)$ provides opportunities to enrich the repertoire of lexical and syntactic structures of legal English, whereas participation in international projects (41\%) exposes participants to a broad spectrum of activities pertaining to the development of communicative competences and, most importantly, to raising participants' motivation and self-confidence to further advance their English. Interestingly, reading fiction (21\%) is where gender becomes relevant as it is preferred more by female participants. Assuming that adult learners, in this case legal practitioners, usually have limited availability of time (see Table 3) for participation in in-service courses, informal practices could provide teachers with the extra scope for competence development to be incorporated in the in-service competence development. Such incorporation could take the form of e-learning, diary writing or other self-study activities.

\section{Self-assessment of communicative skills and competences in general and legal English}

Further in the analysis of legal practitioners' communicative needs it is of utmost importance to examine how participants themselves evaluate their current skills and competences of English. Participants, first of all, were asked to assess their skills of general English (see Figure 4) and then the skills related to legal English (see Figure 5) by indicating whether they consider these skills and competences as adequate for their work contexts, inadequate or whether they have not been exposed to any development of these particular skill and competences.

Responses indicating participants' satisfaction with the offered categories of skills and competences exceed to a greater or a lesser extent the other two options of responses in all of the categories except for the skills of intercultural communication. Thus around half of the participants, the numbers ranging from $42 \%$ to $64 \%$, believe that they have developed the adequate level of general written communication (42\%), application of grammar rules (47\%), oral production in general English (52\%) as well as reading and listening comprehension (64\%). Receptive skills, i.e. reading and listen- 
Perspectives in Legal English In-Service Education: Needs Analysis...

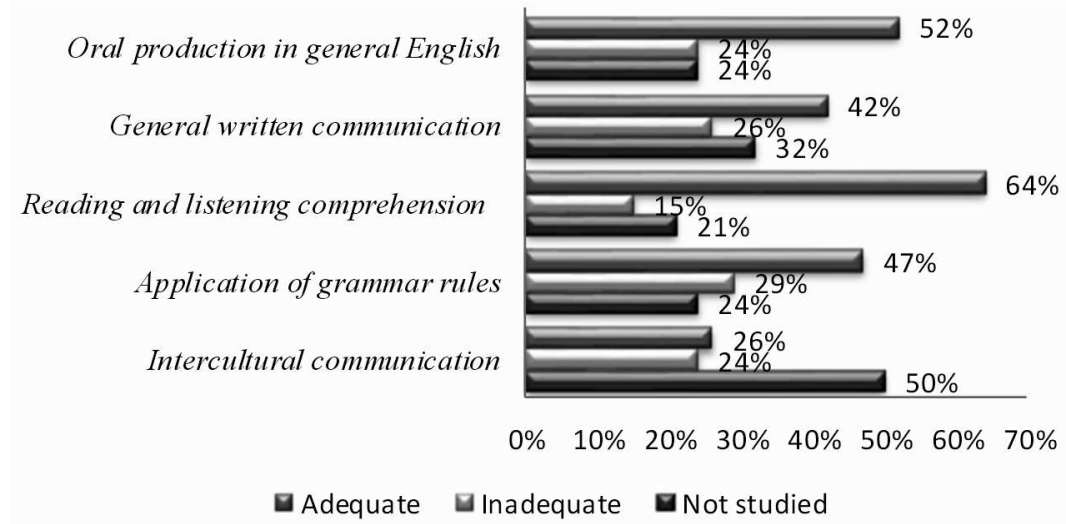

Figure 4. Self-assessment of communicative skills and competences in general English

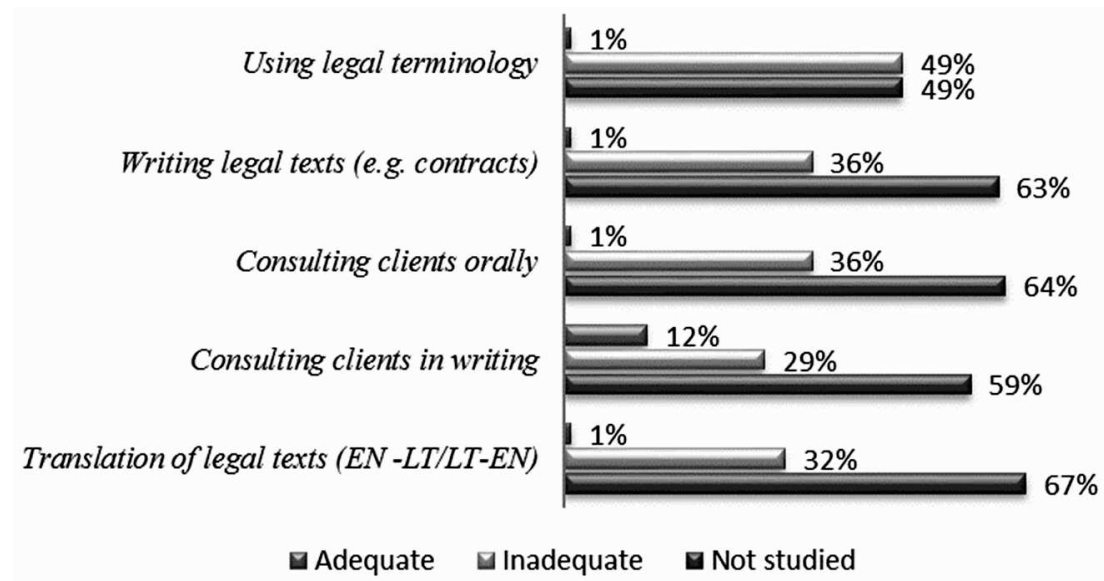

Figure 5. Self-assessment of communicative skills and competences in Legal English

ing, are seen by participants as better developed, while productive skills, especially those of written production, appear to be lagging behind. However, despite the overall larger numbers indicating satisfaction, the responses showing inadequacy or the absence of particular skills are rather numerous so that around a quarter of participants either have not acquired the adequate level of the skills or have not been given a chance to develop them.

Given the high complexity of legal English discourse, or legalese, failure to have a strong foundation of general English, e.g. knowledge and skills in the use of grammar, lexical, stylistic and syntactic structures, could decisively prevent one from building the adequate competences of legal English, let alone from building the feeling of self-confidence with using English in 
legal contexts. Likewise, the responses in the category of intercultural communication disclose a serious problem in preparation of legal practitioners for work under the circumstances of increasing internationalisation of legal practices. Only a quarter of participants (26\%) feel comfortable with their intercultural communication skills, around the same number (24\%) believe that their intercultural communication skills have not been developed to a satisfactory level, while half of participants have not been exposed to the development of such skills at all. In the interviews, participants frequently indicated that numbers of foreign clients and partners, countries of cooperation, transnational projects are increasing, which requires not only an impeccable command of English, but also a good understanding of cultural norms, body language and other means of demeanour. Consequently, nowadays the lack of intercultural communication skills could be a serious obstacle in the successful progress of Lithuanian law companies and legal practitioners.

While participants' self-assessment of general English skills and competences does not present a very favourable overall view, their assessment of skills and competences of legal English depict an even more troublesome picture (see Figure 5).

The responses showing participants' satisfaction with the current competences are minimal with only $1 \%$ in almost all categories, namely using legal terminology, writing legal texts, consulting clients orally and translation of legal texts into English and Lithuanian. Only in the category of consulting clients in writing do the responses of 'adequate' reach $12 \%$, which appears just a scant consolation in the overall unfavourable view of participants' legal English. Furthermore, in most cases participants' confession that they have not been given a possibility to develop these legal English skills and competences strongly dominates. Using legal terminology is the category with the highest score of 'inadequate' (49\%), which means that half of the participants have indeed studied legal terminology but do not regard the competences acquired as adequate for their professional needs. As a result, it can be assumed that in terms of legal English, university study programmes mostly focus on legal terminology, thus, on the one hand, disregarding the development of other communicative competences and, on the other hand, however, not even providing students with the proficiency in using legal terminology which would be satisfactory for their legal practice.

There could be two explanations for such overall negative results in Figure 5. Firstly, it can be supposed that the development of communicative skills of English offered by institutions of formal education (where most of the participants gained their English competences, see Figure 2) do not pro- 
vide students with the necessary skills and competences of English for their work in legal contexts. On the other hand, given that the Figure presents the self-assessment results, it could also be assumed that participants' aspirations and their demands raised regarding their own competences of English are so high that even the quite advanced competences could be assessed by them as inadequate. Be it one way or another, a conclusion can be drawn that to feel more comfortable and more self-confident with their English at work, participants need to improve their Legal English skills and competences in careful consideration of their particular work routines that require English.

\section{Demands of communicative competences of English}

Having examined the actual competences of English that participants believe to possess, it is necessary to take a further step in scrutinising what functions of English participants deem as most significant in their work (Table 1), what intentions with regard to their improvement they cherish (Table 2) and what obstacles they face (Table 3). The answers to these questions were elicited by open questions thus allowing participants to freely disclose their opinions.

\section{Table 1}

Functions of English most necessary in participants' work context

\begin{tabular}{|l|c|}
\hline Use general English for oral communication & $32 \%$ \\
\hline Consult and interact with clients in writing and orally & $32 \%$ \\
\hline Use rich legal terminology & $21 \%$ \\
\hline Translate legal texts & $21 \%$ \\
\hline Write legal texts and documents & $21 \%$ \\
\hline Prepare contracts & $<1 \%$ \\
\hline Reading and listening comprehension & $<1 \%$ \\
\hline Write general correspondence & $<1 \%$ \\
\hline Use Legal English & $<1 \%$ \\
\hline Establish intercultural communication & $<1 \%$ \\
\hline Interact with colleagues from other countries & $<1 \%$ \\
\hline Write legal conclusions & $<1 \%$ \\
\hline Communicate orally and in writing & $<1 \%$ \\
\hline Use English on computer & $<1 \%$ \\
\hline Listen to and comprehend conference papers & $<1 \%$ \\
\hline Perform interpretation in legal context & $<1 \%$ \\
\hline
\end{tabular}


Edita Bartnikaitè, Vilma Bijeikienè

Table 2

Skills of English most in need of improvement among participants

\begin{tabular}{|l|c|}
\hline Speaking & $41 \%$ \\
\hline Fluency in legal terminology & $26 \%$ \\
\hline Writing general correspondence and generating a legal text & $21 \%$ \\
\hline Communication in general English & $<1 \%$ \\
\hline Communication in Legal English & $<1 \%$ \\
\hline Consulting clients in writing and orally & $<1 \%$ \\
\hline All skills & $<1 \%$ \\
\hline General comprehension & $<1 \%$ \\
\hline Grammar & $<1 \%$ \\
\hline Listening & $<1 \%$ \\
\hline Intercultural communication & $<1 \%$ \\
\hline Mediation and interpretation in legal context & $<1 \%$ \\
\hline
\end{tabular}

Table 3

Obstacles to improve English faced by participants

\begin{tabular}{|l|c|}
\hline Lack of time & $85 \%$ \\
\hline Lack of lecturer's didactic competence & $<1 \%$ \\
\hline Lack of practice & $<1 \%$ \\
\hline Lack of willingness/motivation & $<1 \%$ \\
\hline Lack of specialized courses & $<1 \%$ \\
\hline No obstacles & $<1 \%$ \\
\hline Lack of time to do homework and individual study & $<1 \%$ \\
\hline High price of quality language courses & $<1 \%$ \\
\hline
\end{tabular}

As demonstrated in Table 1, legal practitioners encounter a broad spectrum of English uses in their daily work practice. Some of these functions, like establishing intercultural communication or interacting with colleagues from other countries, must have arisen from the increasing internationalisation of legal practices in Lithuanian context. Other functions, such as listen to and comprehend conference papers, demonstrate versatility of roles and activities that lawyers undertake in the context of today's legal practice. However, out of the diverse list five can be singled out as indicated by over $21 \%$ of the participants. The top scoring functions $(32 \%)$ include use 
general English for oral communication as well as consult and interact with clients in writing and orally. These functions importantly relate to productive skills, while following participants' self-assessment they feel more comfortable with receptive skills and less comfortable with productive ones (see Figure 4). The need to improve productive skills is also evident from Table 2 where participants express their opinion about the skills of English they want to improve.

Speaking (41\%) and writing general correspondence and generating a legal text (21\%) are top scoring skills in participants' view. Moreover, participants express eagerness to advance their skills of using legal terminology $(26 \%)$ fluently, which supports the result of their self-assessment (see Figure 5) where they reveal that the competence of using legal terminology was not developed to a satisfactory level.

As far as the obstacles in the way of improving English skills are concerned, vast majority of participants point to the lack of time. It should not be a surprising result for adult learners, however, it is an important signal for their teachers to find ways and methods to shape out in-service English competence development to exploit most productively the scares available time.

\section{Conclusions}

For legal practitioners to arrive at the desired level of English, in other words, to feel comfortable with English in their various work contexts, learning English in their study programmes of formal education including secondary and tertiary does not suffice. Likewise, catching up with English exclusively through the non-formal forms of communicative competence development like in-service courses or courses for the public will not suffice either. The most optimal option to gain adequate competences of English is a combination of formal and non-formal education. Learning English in institutions of secondary and tertiary education should provide learners with strong basis of the language system and fluency in the use of general English and to some extent legal English. Meanwhile, in-service courses can adhere to the most relevant and immediate needs of legal practitioners which can only manifest themselves in the course of legal practice. That is to say, the maturity in one's professional expertise generates the need in the adequate maturity of one's communicative competence and linguistic repertoire in their L1 as well as in other languages the legal practitioner intends to use in his or her work. 
In line with the principles of andragogy, development of in-service English courses for legal practitioners requires a high degree of flexibility and sensitivity to the particular aims and possibilities of the learners. Flexibility should be observed: in the choice of content and complexity of the course (i.e. maximising the correspondence of content to learners' needs and complexity to learners' level), in the degree of integration of general and legal English (i.e. disregarding learners' claims that they just need legal English when gaps in the application of grammar or other communicative skills are evident), in diversification of methodology (e.g. using blended and distance learning in response to learners limited availability of time for the attendance of courses), in exploiting participants' content knowledge (i.e. allowing the content expertise of the learners to influence the content of the English course bringing it close the learners' needs). Finally, to echo legal practitioners' demands and expectations of English in their professional activities better cooperation between the educational institution as a supplier of in-service language development and law companies is an important prerequisite to the development of courses most relevant to their needs.

\section{N O T E}

1 The Department of Statistics of Lithuania, http://osp.stat.gov.lt

\section{R E F E R E N C E S}

Cheng, W., Cheng, L. 2014. Epistemic modality in court judgments: A corpusdriven comparison of civil cases in Hong Kong and Scotland. English for Specific Purposes, 33, 15-26.

Chovancova, B. 2013. Legal Minds Think Alike: Legal English Syllabus Design and the Perceived Language Needs of Present and Former Students of Law. ACC Journal, Technical University in Liberec, 2013, Vol. 19, No. 3: 54-60.

Communication From The Commission To The European Parliament, The Council, The European Economic And Social Committee And The Committee Of The Regions. 2015. European Commission. http://ec.europa.eu/education/ documents/et-2020-draft-joint-report-408-2015_en.pdf

Galbraith, M. W. 2004. Adult Learning Methods: A Guide for Effective Instruction. Malabar: Krieger Publishing Company.

Hafner, C. A. 2013. The discursive construction of professional expertise: Appeals to authority in barrister's opinions. English for Specific Purposes, 32(3): 131143. 
Perspectives in Legal English In-Service Education: Needs Analysis...

Hartig, A. J., Lu, X. 2014. Plain English and legal writing: Comparing expert and novice writers, English for Specific Purposes, 33, 87-96.

Huhta, M., Vogt, K., Johnson, E., Tulkki, E. 2013. Needs Analysis for Language Course Design: A Holistic Approach to ESP. Cambridge: Cambridge University Press.

Jarvis, P. 2012. Adult learning in the social context. New York: Routledge.

Knowles, M. S., Holton, E. F., Swanson, R. A. 2015. The Adult Learner: The Definitive Classic in Adult Education and Human Resource Development. New York: Routledge.

Litosseliti, L., (ed.) 2010. Research Methods in Linguistics. London: Continuum International Publishing Group.

Smith, M. K. 2002. Malcolm Knowles, informal adult education, self-direction and andragogy, the encyclopedia of informal education. www.infed.org/thinkers/ et-knowl.htm

Shuy, R. W. 2001. Discourse Analysis in the Legal Context. In The Handbook of Discourse Analysis, ed. Schiffrin, D., Tannen, D., and Hamilton, D.E. Malden: Blackwell Publishing Ltd., 437-452.

Tough, A. 1979. The Adult's Learning Projects, 2nd ed. Toronto: Ontario Institute of Studies in Education. 